\begin{tabular}{|c|c|}
\hline Title & Encapsulation of Sr-loaded titanate spent adsorbents in potassium al uminosilicate geopolymer \\
\hline Author(s) & $\begin{array}{l}\text { Soonthornwiphat, Natatsawas; Kobay ashi, Y utaro; Toda, Kanako; Kuroda, Kazuma; Islam, Chaerun Raudhatul; Otake, } \\
\text { T subasa; Elakneswaran, Y ogarajah; Provis, John L.; Sato, T sutomu }\end{array}$ \\
\hline Citation & $\begin{array}{l}\text { Journal of Nuclear Science and Technology, 57(10), 1181-1188 } \\
\text { https://doi.org/10.1080/00223131.2020.1775717 }\end{array}$ \\
\hline Issue Date & $2020-10-02$ \\
\hline Doc URL & http:/hdl.handle.net/2115/82853 \\
\hline Rights & $\begin{array}{l}\text { This is an A ccepted Manuscript of an article published by Taylor \& Francis in Journal of Nuclear Science and } \\
\text { Technol ogy on 02 Oct 2020, available online: http://www.tandfonline.com/10.1080/00223131.2020.1775717. }\end{array}$ \\
\hline Type & article (author version) \\
\hline File Information & Encapsulation of Sr-Ioaded Titanate Spent A dsorbents in Potassium A luminosilicate Geopolymer-for JNST_final.pdf \\
\hline
\end{tabular}

Instructions for use 


\section{ARTICLE \\ Encapsulation of Sr-loaded Titanate Spent Adsorbents in Potassium Aluminosilicate Geopolymer}

Natatsawas Soonthornwiphat ${ }^{\mathrm{a}}$, Yutaro Kobayashi ${ }^{\mathrm{a}}$, Kanako Toda ${ }^{\mathrm{a}}$, Kazuma Kuroda ${ }^{\mathrm{a}}$, Chaerun

Raudhatul Islam ${ }^{\mathrm{a}}$, Tsubasa Otake ${ }^{\mathrm{b}}$, Yogarajah Elakneswaran ${ }^{\mathrm{b}}$, John L. Provis ${ }^{\mathrm{c}}$ and Tsutomu Sato $^{b^{*}}$

${ }^{a}$ Graduate School of Engineering, Hokkaido University, Kita13, Nishi 8, Sapporo, Hokkaido, 060-8628, Japan;

${ }^{\mathrm{b}}$ Faculty of Engineering, Hokkaido University, Kita 13, Nishi 8, Sapporo, Hokkaido, 060-8628, Japan;

${ }^{\mathrm{c}}$ Department of Materials Science \& Engineering, The University of Sheffield, Sheffield, S1

\section{JD, United Kingdom}

Titanate adsorbents have been used to remove Sr radioisotopes from contaminated water at the Fukushima Daiichi Nuclear Power Station site. This process leads to the generation of spent adsorbents, which require stabilization for long term storage and disposal. Geopolymers are candidates for matrices to achieve this consolidation. However, more data are needed to assess the leaching behavior of $\mathrm{Sr}$ from the adsorbents embedded in a geopolymer matrix. In this study, leaching experiments and observations of the Sr distribution of spent titanate adsorbent embedded in geopolymers, loaded with $\mathrm{Sr}$ at realistic concentrations were conducted. The experimental results illustrate that only $0.75 \%$ of the $\mathrm{Sr}$ was leached out from a K-geopolymer loaded with $30 \%$ (by solid weight) of spent adsorbent after 360 days of immersion in deionized water. From the observations of Sr distributions by electron and isotope microscopy, Sr remained in the titanate adsorbent and did not diffuse into

\footnotetext{
*Corresponding author. Email: tomsato@eng.hokudai.ac.jp
} 
the geopolymer matrix. Leaching of $\mathrm{Sr}$ (loaded at a similar concentration) from the K-geopolymer without the adsorbent was also limited, only $0.05 \%$ after 360 days of leaching. In conclusion, both titanate adsorbent in K-geopolymer matrix, and the K-geopolymer itself, offer an attractive potential for Sr immobilization.

Keywords: adsorption; decontamination; Fukushima Daiichi Nuclear; ion exchange; radioactive waste management; strontium; alkali activated material; geopolymer; titanate adsorbent 


\section{Introduction}

Since the Fukushima Daiichi Nuclear Power Station (FDNPS) was significantly damaged the high magnitude earthquake and consequent tsunami in 2011, a huge amount of water has been injected to cool the resulting fuel debris. This coolant water is contaminated with radionuclides from inside the nuclear reactor, and it has therefore been necessary to decontaminate the water to enable repeated use of the water in the circulating water-cooling system that was established. In the decontaminating/circulating system, sodium titanate as an inorganic ion exchanger has been used to absorb and remove radionuclides, especially ${ }^{90} \mathrm{Sr}$, from contaminated water with a high decontamination factor in the recirculating system. High removal efficiency has been demonstrated for $\mathrm{Sr}$ by sodium titanate compound [1-5]. However, large volumes of the spent adsorbent loaded with $\mathrm{Sr}$ have been stored in a temporary radioactive waste storage site at the FDNPS awaiting conditioning for solidification prior to the disposal.

Suitable methods for encapsulation and long-term safe storage of these spent ion exchanger adsorbents have been investigated to determine the formation of monolithic solidified waste forms, as a key requirement for any conditioning process. The available options for the solidification process and materials, such as vitrification, solidification with cementitious materials, and solidification with alkaline activated materials, are being considered. Vitrification involves thermal treatment, and unavoidable generation of gases and secondary wastes present drawbacks for this process [6]. Conventional cementitious material is an attractive option due to a simple manufactural process and minimal secondary waste generation. However, high free water content which may induce problematic hydrogen generation, low resistance to acid and fire conditions, and incompatibility with several types of waste have been noted as disadvantages of conventional cementitious materials [7-11].

An alternative option is offered by alkaline activated materials known as "geopolymers". The alkaline activated materials can be designed to include desirable properties such as excellent 
thermal resistance, high and durable performance characteristics and stability against chemical attack, as well as a low content of free water. Geopolymer is synthesized by the reaction between an aluminosilicate precursor and an alkaline activator through a process involving dissolution, polycondensation, and hardening [12-15]. The resulting $\mathrm{AlO}_{4}-\mathrm{SiO}_{4}$ structure of the geopolymer that forms during the rearrangement process results in a net negatively charged framework (as in other aluminosilicate frameworks, zeolites), where cations needed to balance the charge, and the structural similarity of geopolymers to zeolites makes them candidates to participate in ion exchange with charge balancing cations [16-17]. Recently, Ke et al. [18] determined the distribution of $\mathrm{Sr}$ in a geopolymer with embedded titanate adsorbents at high $\mathrm{Sr}$ concentrations. The formation of $\mathrm{SrCO}_{3}$ from high concentrations of $\mathrm{Sr}$ was observed to play an important role in immobilizing the $\mathrm{Sr}$ inside the waste form generated. That study showed a strong potential for safe storage of $\mathrm{Sr}$ in geopolymer waste form even at high Sr concentrations. However, the study does not fully elucidate the behavior at immobilization of low concentrations of $\mathrm{Sr}$, which relates to the actual conditions where radiation dose rates limit the concentration of $\mathrm{Sr}$ radioisotopes in intermediate level waste to be low. Additionally, there are no data available for the long-term leaching behavior of $\mathrm{Sr}$ from this type of waste, especially considering the contrasting chemical interactions between the titanate adsorbent and geopolymer matrix.

In this context, the purpose of this present study is to investigate the leaching behavior and encapsulation mechanisms of $\mathrm{Sr}$ in titanate adsorbent embedded in a geopolymer waste form. The titanate adsorbent is loaded with a low concentration of non-radioactive $\mathrm{Sr}$, to replicate the actual conditions in this study. Alkali-activated metakaolin with potassium silicate activator was applied as the waste matrix for encapsulation of the adsorbent. Leaching experiments in deionized water, and a microanalysis of the specimens after different leaching periods, were also conducted.

\section{Materials and Methods}




\subsection{Materials and sorption}

The SrTreat ${ }^{\circledR}$ used in the experiments here is a commercial hydrous sodium titanate used as a strontium selective ion exchanger (Fortum Power and Heat Oy, Finland). The titanate is a water-insoluble white granular product with a chemical composition $\mathrm{Na}_{\mathrm{a}} \mathrm{Ti}_{\mathrm{b}} \mathrm{O}_{\mathrm{c}} \cdot \mathrm{xH}_{2} \mathrm{O}$ and grain sizes between 0.3 to $0.85 \mathrm{~mm}$. The adsorption process to load $\mathrm{Sr}^{2+}$ on the ion exchanger was conducted by exposing the ion exchanger to a non-radioactive $3.3 \mathrm{ppm}(37.65 \mu \mathrm{M})$ solution of $\mathrm{SrCl}_{2} \cdot 6 \mathrm{H}_{2} \mathrm{O}$ (Wako Pure Chemical Industries, Ltd., Osaka, Japan) at a ratio of ion exchanger mass to solution volume of 1:100 $(\mathrm{g} / \mathrm{mL})$, and shaking at $160 \mathrm{rpm}$ for 24 hours. Then, the granules were separated by filtration and dried at ambient temperature till achieving a constant weight.

\subsection{Manufacture of solidified waste form}

Alkaline-activated binder components for geopolymer specimens were produced by the reaction between an alkaline activator solution and metakaolin (Metastar ${ }^{\circledR}$ 501, Imerys, UK) as aluminum and silica sources $\left(\mathrm{SiO}_{2}: 51.75 \mathrm{wt} . \%, \mathrm{Al}_{2} \mathrm{O}_{3}: 43.87 \mathrm{wt} . \%\right.$, and some trace elements). The XRD pattern of the metakaolin is shown in Figure 1, the spectrum has a broad peak at around $22^{\circ} 2 \theta$ due to structural disorder of the metakaolin, and peaks from minor crystalline phases anatase, quartz, and mica as impurities. The alkaline activator solution was prepared by dissolving $\mathrm{KOH}$ (Wako Pure Chemical Industries, Ltd., Osaka, Japan) pellets into a commercial potassium silicate solution (Wako Pure Chemical Industries, Ltd., Osaka, Japan) to reach a final $\mathrm{SiO}_{2} / \mathrm{K}_{2} \mathrm{O}$ molar ratio of solution equal to 1.0 , and adding distilled water to give a constant $\mathrm{H}_{2} \mathrm{O} / \mathrm{K}_{2} \mathrm{O}$ ratio in each sample. The final stoichiometry of sample is $\mathrm{K}_{2} \mathrm{O} \cdot \mathrm{Al}_{2} \mathrm{O}_{3} \cdot 3 \mathrm{SiO}_{2} \cdot 11 \mathrm{H}_{2} \mathrm{O}$, which is followed by our previous studies to achieve a dense and stable gel matrix [18-19]. The same activator was used for all samples. The mixing process involved mixing the loaded ion exchanger with metakaolin at a mass ratio of 0.30 , then adding the prepared alkaline activator solution to form the geopolymer paste. The mixtures were manually blended for 15 minutes using a glass rod, and then cast in cylindric $1.3 \mathrm{~cm}$ 
diameter and $1.5 \mathrm{~cm}$ high molds, with the lid of each mold tightly sealed by Parafilm. The specimens were cured at $40{ }^{\circ} \mathrm{C}$ for 24 hours followed by 24 hours at $25^{\circ} \mathrm{C}$.

Geopolymer with Sr but with no adsorbent, and conventional cement pastes including Sr with and without adsorbent, were also prepared and used for comparison. For the geopolymer materials without adsorbent, the calculated powder amount of $\mathrm{SrCl}_{2} \cdot 6 \mathrm{H}_{2} \mathrm{O}$ was dissolved in water before mixing with the alkaline activator solution, to obtain $2.25 \mu \mathrm{mol} \mathrm{Sr}^{2+}$ in each specimen (assumed as the same calculated amount of $\mathrm{Sr}^{2+}$ in the adsorbent including to each geopolymer), then mixed with metakaolin and molded by the same methods as for the geopolymer matrices with adsorbents. Cement paste samples were prepared by mixing the loaded ion exchanger with ordinary Portland cement (standard material " $211 \mathrm{~S}$ " provided by Japan Cement Association) at a mass ratio of 0.30. Then, water was added to give a liquid to solid (OPC and adsorbent) ratio of 0.35 . For the cement paste without adsorbent, the calculated powder amount of $\mathrm{SrCl}_{2} \cdot 6 \mathrm{H}_{2} \mathrm{O}$ was dissolved in the water before mixing the sample, to obtain $2.25 \mu \mathrm{mol} \mathrm{Sr}{ }^{2+}$ in each specimen. The fresh mixture was molded and sealed like the geopolymer specimens and cured at ambient temperature for four weeks.

$<$ Figure 1 $>$

\subsection{Leaching experiments}

Leaching experiments were conducted to investigate the leaching behavior of $\mathrm{Sr}$ after immersing into deionized water. The ANSI/ANS-16.1-2003 standard test [20] was applied. Each specimen was immersed in $88 \mathrm{~mL}$ distilled water as leachant (the ratio of leachant volume to specimen surface area is $10 \mathrm{~mL} / \mathrm{cm}^{2}$ ) and the leachant was completely replaced after cumulative leach times of 2 hours, 7 hours, and 1, 2, 3, 4, 5, 19, 47, 90, 150, 210, 270, 330 , and 360 days from the start of the test. Leachate strontium concentrations were determined to measure the released fractions, and solid specimens were removed at 19, 90, and 360 days of leaching time for a solid phase analysis.

\subsection{Liquid-phase analysis}


The solution, after sorption of $\mathrm{Sr}$ onto the ion exchanger, and the leachate at each timestep in the leaching experiment, were analyzed by inductively coupled plasma-mass spectroscopy (ICP-MS) (iCAP Q ICP-MS, Thermo scientific, USA) to determine the Sr concentration and obtain the leaching rates of $\mathrm{Sr}$ from the specimens. The $\mathrm{pH}$ values of the liquid samples were also determined.

\subsection{Solid-phase analysis}

To identify changes in the crystalline phases of the ion exchanger before and after loading with $\mathrm{Sr}^{2+}$, and also in the solidified waste form incorporating $\mathrm{Sr}^{2+}$ before and after the leaching, the samples were ground in a mortar and measured by X-ray diffractometry (XRD) (Rigaku X-Ray Diffractometer, Rigaku, Japan) with $\mathrm{Cu}-\mathrm{K} \alpha$ radiation at $30 \mathrm{kV}$ and $20 \mathrm{~mA}$, and a $2 \theta$ scan range of $2^{\circ}$ to $70^{\circ}$. The chemical composition of sectioned polished sample surfaces were observed using scanning electron microscopy (SEM) with energy dispersive X-ray spectroscopy (EDX) (JSM-IT200, JEOL, Tokyo, Japan), operated at the acceleration voltage of $15 \mathrm{kV}$, and an isotope microscope by secondary ion mass spectrometry (SIMS) (CAMECA IMS-1270, CAMECA, France). For the microscopic imaging, the samples were Pt-coated to increase electric conductivity using an ion sputtering device (JFC-1100E, JEOL, Tokyo, Japan) at a discharge current of $10 \mathrm{~mA}$, with coating time $120 \mathrm{sec}$.

\section{Results and Discussion}

\subsection{Characterization of the titanate adsorbent}

The titanate adsorbent is an inorganic ion exchanger which has a layered structure of titanium-oxygen octahedral sheets. Between the sheet layers there is sodium which forms a hydrous sodium titanate structure [18,21]. These sodium ions are readily exchangeable, and the layered structure gives a large surface area with the high amount of interlayer water and relatively open layered structure. These characteristics support the efficiency of the ion exchange reaction between $\mathrm{Na}^{+}$and other more-preferred cations [2-4,22-23]. The $\mathrm{Sr}^{2+}$ has a higher valence than that of $\mathrm{Na}^{+}$, and the substitution of multivalent for monovalent cations 
will decrease the number of ions between the interlayer of the titanate sheets and will lead to a shrinking of the layer spacing making the layered structure more stable [3,24-29]. These characteristics make the adsorption of $\mathrm{Sr}^{2+}$ on titanate adsorbents highly selective when compared to alkali metal ions, almost all of the $\mathrm{Sr}^{2+}$ exchangeable with $\mathrm{Na}^{+}$in the sorbent with remaining $\mathrm{Na}^{+}$mainly left on the titanate adsorbent as expressed in Equation (1).

$$
\mathrm{Na}_{\mathrm{a}} \mathrm{Ti}_{\mathrm{b}} \mathrm{O}_{\mathrm{c}}+\mathrm{n} \mathrm{Sr}^{2+} \rightleftharpoons \mathrm{Na}_{\mathrm{a}-2 \mathrm{n}} \mathrm{Sr}_{\mathrm{n}} \mathrm{Ti}_{\mathrm{b}} \mathrm{O}_{\mathrm{c}}+2 \mathrm{n} \mathrm{Na}^{+}
$$

Protons released through water self-ionization can also participate in ion exchanges, resulting in a protonated or hydrated product (Equation (2)). Here the $\mathrm{H}^{+}$is a small cation that is strongly adsorbed, since it can move close to the active site of the adsorbent and obstruct the ion exchange with $\mathrm{Sr}^{2+}$. Therefore, low $\mathrm{pH}$ systems are not suitable for this adsorbent. This is the reason high $\mathrm{pH}$ systems such as geopolymers and cementitious matrices are proposed to hold the Sr ions in the interlayer structure of the titanate $[21,28]$.

$$
\mathrm{Na}_{\mathrm{a}} \mathrm{Ti}_{\mathrm{b}} \mathrm{O}_{\mathrm{c}}+\mathrm{x} \mathrm{H} \mathrm{H}_{2} \mathrm{O} \rightleftharpoons \mathrm{Na}_{\mathrm{a}-\mathrm{x}} \mathrm{H}_{\mathrm{x}} \mathrm{Ti}_{\mathrm{b}} \mathrm{O}_{\mathrm{c}}+\mathrm{x} \mathrm{Na} \mathrm{Na}^{+}+\mathrm{x} \mathrm{OH}^{-}
$$

The XRD patterns of the titanate adsorbent before and after loading with $\mathrm{Sr}^{2+}$ are shown in Figure 2. The titanate adsorbent is identified as a long-range disordered (X-ray amorphous) material, with the broad feature at around $9^{\circ} 2 \theta$ indicating the interlayer spacing of the main edge-sharing $\mathrm{TiO}_{6}$ sheets $[18,30]$. With no significant difference in XRD patterns before and after $\mathrm{Sr}$ adsorption, this indicates that no new phases have formed, and there are no identifiable crystallographic changes occurring as a result of the adsorption processes. For the samples including the loaded titanate adsorbent in the geopolymer matrix, the interaction between titanate adsorbent and the matrix, and the $\mathrm{Sr}$ distribution after leaching, are investigated and discussed in more detail in the following section.

$$
<\text { Figure } 2>
$$

\subsection{Leaching rates and distribution of $\mathrm{Sr}$}

Figure 3 shows the leaching rate of $\mathrm{Sr}^{2+}$ from the geopolymer containing loaded adsorbent. 
The initial leaching period, within the first 5 days, showed relatively rapid leaching of $\mathrm{Sr}^{2+}$. This situation can be explained as $\mathrm{Sr}^{2+}$ wash-out from the superficial parts of the adsorbent particles located near the binder surface, including effects of hydrolysis due to the high selectivity of $\mathrm{H}^{+}$on titanate adsorbent [21] according to Equation (3), when the very alkaline geopolymer was placed into a neutral $\mathrm{pH}$ environment.

$$
\mathrm{Sr}_{\mathrm{a}} \mathrm{Ti}_{\mathrm{b}} \mathrm{O}_{\mathrm{c}}+2 \mathrm{n} \mathrm{H} \mathrm{H}_{2} \mathrm{O} \rightleftharpoons \mathrm{Sr}_{\mathrm{a}-\mathrm{n}} \mathrm{H}_{2 \mathrm{n}} \mathrm{Ti}_{\mathrm{b}} \mathrm{O}_{\mathrm{c}}+\mathrm{n} \mathrm{Sr}^{2+}+2 \mathrm{n} \mathrm{OH}^{-}
$$

During the 360 days of the leaching experiment, $0.75 \%$ of the $\mathrm{Sr}^{2+}$ leached out from the specimen to the leachate (calculated on the basis of the known amount of Sr uptake in the sorbent particles). This shows a high retention performance and limitation by diffusion for $\mathrm{Sr}^{2+}$ in the geopolymer matrices with titanate adsorbents, potentially due to the high $\mathrm{pH}$ conditions.

$<$ Figure $3>$

The XRD patterns of the K-geopolymer with spent titanate adsorbent before and after leaching are shown in Figure 4. The broad hump centered at around $28^{\circ} 2 \theta$ is characteristic of potassium aluminosilicate geopolymer phases [31,32], and the small crystalline peaks of anatase and quartz from the metakaolin precursor are also present. Similarly, there is no difference in the patterns between those before and after the leaching for the different periods, indicating that there was no formation of new crystalline products in this experimental system.

\section{$<$ Figure $4>$}

The SEM images and elemental maps of the geopolymer specimens with embedded loaded titanate adsorbent $\mathrm{Sr}$ before and after leaching for different durations are shown in Figure 5. The Ti-rich regions are the adsorbent particles, with the clearly distinguished distribution boundary between adsorbent and matrix, indicating the absence of any interaction that could lead to a breakdown and release of Ti from the titanates between adsorbent and geopolymer 
matrix during the manufacturing (geopolymerization) and leaching processes. This is consistent with the results of Ke et al. [18]. There Al- and Si-rich areas consistent with geopolymer regions have no $\mathrm{Ti}$, also indicating no specific interaction. Kuenzel et al. [33] observed the interaction between zeolite (clinoptilolite) and geopolymer matrix, and considered that in those forms, an interfacial alteration zone forming between the zeolite particle and the bulk geopolymer could act as a barrier to aid retention of Cs in the adsorbent. When focusing on Na- and $\mathrm{K}$ - rich areas in the results presented here, $\mathrm{Na}$ and $\mathrm{K}$ were mainly distributed in (respectively) the titanate adsorbent and the geopolymer matrix before leaching. However, as the samples age and are leached, the maps show the $\mathrm{Na}$ and $\mathrm{K}$ distribution becoming indistinct. This indicates that $\mathrm{Na}$ in the titanate adsorbent exchanged for $\mathrm{K}$ supplied by the geopolymer matrix during the leaching experiment; even though the titanates are not expected to be selective for $\mathrm{K}^{+}$, the very high concentrations of this ion in the geopolymer pore fluid were sufficient to induce a somewhat high degree of exchange. The $\mathrm{Na}^{+}$released from the titanate can be accepted on the negatively charged sites of Al tetrahedra in the geopolymer matrix by a corresponding cation exchange reaction between $\mathrm{Na}^{+}$and $\mathrm{K}^{+}$during the geopolymerization and leaching processes [16].

\section{$<$ Figure $5>$}

The low concentration of $\mathrm{Sr}^{2+}$ used in this study would be very difficult to detect with SEM-EDX, and so the distribution of $\mathrm{Sr}$ alone in the elemental maps were not possible, and Isotope Microscopy (IM) was employed in this study to obtain Sr isotope maps. The IM is a device that uses Secondary Ion Mass Spectroscopy (SIMS) technology to provide distribution maps of isotopes in materials and which offers a much lower detection limit than SEM-EDX. The system used here has a spatial resolution of $200 \mathrm{~nm}$ in the lateral direction and $10 \mathrm{~nm}$ in the depth direction for isotopes up to a concentration of $1 \mathrm{ppb}$, which is adequate to provide an image of the trace element distribution on the surface of the samples within a small spot size for high precision isotopic imaging [34-35]. Figure 6 shows maps of the ${ }^{48} \mathrm{Ti}$ and ${ }^{88} \mathrm{Sr}$ 
isotopes at selected regions around the center of the geopolymer specimens containing loaded adsorbent before and after leaching. The Ti-rich area indicates the adsorbent particle, and its $\mathrm{Sr}$ isotope intensity and distribution remain essentially unchanged even after 360 days of leaching. These isotope maps suggest that almost all of the $\mathrm{Sr}^{2+}$ was retained within the titanate adsorbent, although $\mathrm{Na}^{+}$was leached out from the adsorbent by cation exchange for $\mathrm{K}^{+}$in the matrix. Relate to this, Ke et al. (2019), working at much higher Sr concentrations, concluded that $\mathrm{Sr}^{2+}$ was retained inside the titanate adsorbents within their geopolymer matrix samples by the formation of $\mathrm{SrCO}_{3}$ due to oversaturation conditions. However, in this study, no formation of $\mathrm{SrCO}_{3}$ was observed, probably due to the undersaturated conditions. As mentioned above, there is also no chemical barrier formation by interaction and alteration between the adsorbent and matrix. In conclusion, it may be assumed that $\mathrm{Sr}^{2+}$ remained in the titanate particles without formation of a specific low solubility phase or chemical barrier, and despite the extensive cation exchange of $\mathrm{Na}^{+}$for $\mathrm{K}^{+}$entering from the matrix. This retention was presumably achieved due to the higher selectivity of divalent $\mathrm{Sr}^{2+}$ than that of the monovalent $\mathrm{K}^{+}$on the adsorption sites of the titanate.

\section{$<$ Figure $6>$}

To compare the efficiencies of the retention of $\mathrm{Sr}^{2+}$ inside the geopolymer matrix, specimens of K-geopolymer without titanate adsorbent and specimens of ordinary Portland cement (OPC) with and without titanate adsorbent were also investigated (Figure 7). Even without the addition of the titanate adsorbent, almost all of the $\mathrm{Sr}^{2+}$ was retained in the geopolymer matrix, indicating that the geopolymer matrix itself offers a high potential to immobilize $\mathrm{Sr}^{2+}$ in case it is released from a loaded exchanger particle (Figure 7, curve a). Only $0.05 \%$ of the $\mathrm{Sr}^{2+}$ leached out from the matrix after 360 days of leaching. At the low concentration of $\mathrm{Sr}^{2+}$, the $\mathrm{Sr}^{2+}$ ions are easily accommodated within the geopolymer gel framework and do not significantly change the local gel structure [36]. This indicates that both the titanate adsorbent in K-geopolymer matrix and the K-geopolymer itself offer a high potential for $\mathrm{Sr}$ 
immobilization.

The leaching ratios of OPC with titanate adsorbent (12.23\% after 360 days in Figure 7, curve c) and without titanate adsorbent (50.63\% after 360 days in Figure 7 , curve d) were very much higher than those the of geopolymer however. With the adsorbent, $\mathrm{Sr}^{2+}$ in the adsorbent may leach out to the matrix by cation exchange with $\mathrm{Ca}^{2+}$ in the pore solution of the OPC matrix. With the similar properties of $\mathrm{Sr}^{2+}$ and $\mathrm{Ca}^{2+}$, the selectivity of $\mathrm{Sr}^{2+}$ and $\mathrm{Ca}^{2+}$ on the titanate layered structure is not significantly different $[21,28]$. In the initial stage of the leaching experiment, the exchange process may proceed due to the steeper activity gradient of $\mathrm{Sr}^{2+}$ and $\mathrm{Ca}^{2+}$ between the adsorbent and the OPC matrix. After the $\mathrm{Sr}^{2+}$ is leached or exchanged from the adsorbent into the cement binder, however, $\mathrm{Sr}^{2+}$ shows a lower preference than $\mathrm{Ca}^{2+}$ for substituting and binding with hydrated phases in cements when in contact with alkaline pore fluid [9]. For this reason, the OPC matrix has a poor ability to prevent the release of $\mathrm{Sr}^{2+}$ which has moved into the OPC matrix. Eventually, much of $\mathrm{Sr}^{2+}$ is leached from the OPC specimens, as shown in the experimental results.

\section{$<$ Figure $7>$}

Finally, the encapsulation mechanisms of the low concentration $\mathrm{Sr}$ in the titanate adsorbent within a K-geopolymer matrix is summarized (Figure 8). The K-geopolymer matrix provides favorable chemical conditions for immobilization of $\mathrm{Sr}^{2+}$ in the adsorbent. First, the K-geopolymer imposes hyperalkaline conditions which are able to completely reduce exchanges by $\mathrm{H}^{+}$. The $\mathrm{H}^{+}$has the highest selectivity among several cations in the following order: $\mathrm{H}^{+}>>\left(\mathrm{Sr}^{2+} \approx \mathrm{Ca}^{2+}\right)>>\mathrm{K}^{+}>\mathrm{Na}^{+}[21]$. This suggests that in a hyperalkaline system, the exchange of $\mathrm{Sr}^{2+}$ for $\mathrm{H}^{+}$is very highly restricted because of the low activity of $\mathrm{H}^{+}$(Figure 8 , b). Second, the K-geopolymer matrix also provides a high-K environment surrounding the adsorbent. Due to the higher cation exchange selectivity of $\mathrm{Sr}^{2+}$ over $\mathrm{K}^{+}, \mathrm{Sr}$ cations are selectively retained in the adsorbent (Figure 8, a), although $\mathrm{Sr}$ cations would easily be leached out from the adsorbent in a high Ca system such as in an OPC matrix. However, in the high 
$\mathrm{pH}$ and $\mathrm{K}$ conditions such as our matrix, the interference by external $\mathrm{Ca}$ is not detrimentally affected the $\mathrm{Sr}$ exchange because competitive calcium concentration is limited at high $\mathrm{pH}$ conditions due to precipitation hydroxide and/or carbonate. Third, metakaolin-based geopolymer provides the sites with a negative charge in the Al-tetrahedra enabling $\mathrm{Sr}$

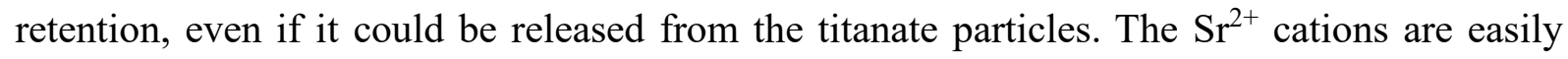
accommodated within a geopolymer gel framework at low concentrations, and do not significantly change the local gel structure [36] (Figure 8, c). Likewise, ionic diffusion and surface dissolution could happen at the edge of specimens (Figure 8, d). Base on this reasoning, this study clearly suggests that a geopolymer structure formed by K-silicate activation of metakaolin offers an excellent form for a waste matrix which limits Sr leaching from loaded titanate adsorbent granules.

$<$ Figure $8>$

\section{Conclusions}

Titanate adsorbents exhibited high selectivity for $\mathrm{Sr}^{2+}$ and maintained their initial physical and chemical properties during embedding (in particulate form) in geopolymer binders, and through the subsequent leaching processes. After encapsulation of the adsorbent with a realistic Sr concentration in a K-silicate-activated metakaolin-based geopolymer, almost all of the $\mathrm{Sr}$ was retained in the adsorbent without formation of precipitating phases or interfacial alterations between the titanate and geopolymer. A low leaching rate of $\mathrm{Sr}(0.75 \%$ released after 360 days of leaching) arises from the hyperalkaline geopolymer pore fluid conditions which limit the $\mathrm{Sr}^{2+}$ exchange by $\mathrm{H}^{+}$, the high $\mathrm{K}$ content of the system further limits leaching out of $\mathrm{Sr}$, and there are sites that strongly fix $\mathrm{Sr}$ by ion exchange onto the geopolymer framework in the event that it is released by the titanate. In addition to other advantages of geopolymer materials such as the excellent thermal resistance, the potential of designs for a relatively low content of free water, and prevention of hydrogen release with its attendant danger of explosion, the low leaching rate of Sr suggests the K-aluminosilicate geopolymer is 
an excellent candidate for a waste matrix in a form that is suitable for long term storage and disposal of spent titanate adsorbent in the proper repository.

\section{Acknowledgements}

This work was supported by EPSRC (UK) under grants EP/P013171/1 and EP/T013524/1, in collaboration with the Nuclear Energy Science \& Technology and Human Resource Development Project (through concentrating wisdom) from the Ministry of Education, Culture, Sports, Science and Technology of Japan (283602), and JICA Innovative Asia scholarship. Also, this work was the result of using research equipment shared in MEXT project for promoting public utilization of advanced research infrastructure (Program for supporting formation of advanced research platforms); Grant Number JPMXS0410300119. We thank Asst. Prof. Naoya Sakamoto, Creative Research Institution, Research Department, Hokkaido University, for help with using isotope microscope and useful discussions. We are also grateful to Fortum and anonymous reviewers for providing the titanate adsorbent and valuable comments for this study, respectively.

\section{Disclosure statement}

No potential conflict of interest was reported by the authors. 


\section{References}

[1] Tusa E. Efficiency of Fortum's Cstreat $\AA$ and Srtreat ${ }^{\circledR}$ in cesium and strontium removal in Fukushima Daiichi Npp. European Nuclear Conference; 2014 May; Marseille, France.

[2] Tusa E. Cesium and strontium removal with highly selective ion exchange media in Fukushima and cesium removal with less selective media - 14018. WM 2014 Conference; 2014 March; Arizona, USA.

[3] Villard A, Siboulet B, Toquer G, Merceille A, Grandjean A, Dufrêche JF. Strontium selectivity in sodium nonatitanate $\mathrm{Na}_{4} \mathrm{Ti}_{9} \mathrm{O}_{20}$ x $\mathrm{H}_{2} \mathrm{O}$. J Harzard Mater. $2015 ; 283: 432-438$.

[4] Izawa H, Kikkawa S, Koizumi M. Ion exchange and dehydration of layered titanates, $\mathrm{Na}_{2} \mathrm{Ti}_{3} \mathrm{O}_{7}$ and $\mathrm{K}_{2} \mathrm{Ti}_{4} \mathrm{O}_{9}$. J Phys Chem. 1982;86:5023-5026.

[5] Kirishima A, Sasaki T, Sato N. Solution chemistry study of radioactive Sr on Fukushima Daiichi NPS site. J Nucl Sci Technol. 2015;52:152-161.

[6] International Atomic Energy Agency. Application of ion exchange processes for the treatment of radioactive waste and management of spent ion exchangers. Vienna: International Atomic Energy Agency; 2002. (Technical reports series No.408).

[7] Mehta PK, Monteiro PJM. Concrete: Microstructure, properties, and materials. $4^{\text {th }}$ ed. McGraw-Hill Education; 2014.

[8] Jang JG, Park SM, Lee HK. Cesium and strontium retentions governed by aluminosilicate gel in alkali-activated cements. Materials. 2017;10:447-459.

[9] Atkins M, Glasser FP. Application of portland cement-based materials to radioactive waste immobilization. J Waste Manag. 1992;12:105-131.

[10] Bart F, Cau-di-Coumes C, Frizon F, Lorente S. Cement-based materials for nuclear waste storage. Springer New York; 2013.

[11] Shi C, Spence R. Designing of cement-based formula for solidification/stabilization of hazardous, radioactive, and mixed wastes. Environ Sci Technol. 2004;34:391-417. 
[12] Provis JL. Geopolymers and other alkali activated materials: why, how, and what? Mater Struct. 2014;47:11-25.

[13] Provis JL, Palomo A, Shi C. Advances in understanding alkali-activated materials. Cement Concrete Res. 2015;78:110-125.

[14] Škvára F, Kopecký L, Němeček J, Bittnar Z. Microstructure of geopolymer materials based on fly ash. Ceram - Silik. 2006;50:208-215.

[15] Duxson P, Lukey GC, Van Deventer JSJ. Physical evolution of Na-geopolymer derived from metakaolin up to $1000^{\circ} \mathrm{C}$. J Mater Sci. 2007;42:3044-3054.

[16] Gasca-Tirado JR, Manzano-Ramírez A, RiveraMuñoz EM, Velázquez-Castillo R, Apátiga-Castro M, Nava R. Ion exchange in geopolymers [Internet]. New Trends in Ion Exchange Studies; 2018 [revised 2018 Nov 1; cited 2019 Dec 2] Available from: https://www.intechopen.com/books/new-trends-in-ion-exchange-studies/ion-exchange-i n-geopolymers

[17] O'Connor SJ, MacKenzie KJD, Smith ME, Hanna JV. Ion exchange in the charge-balancing sites of aluminosilicate inorganic polymers. $\mathrm{J}$ Mater Chem. 2010;20:10234-10240.

[18] Ke X, Bernal SA, Sato T, Provis JL. Alkali aluminosilicate geopolymers as binders to encapsulate strontium-selective titanate ion-exchangers. Dalton $\mathrm{T}$. 2019;48:12116-12126.

[19] Duxson P, Provis JL, Lukey GC, Mallicoat SW, Kriven WM, Van Deventer JSJ. Understanding the relationship between geopolymer composition, microstructure and mechanical properties. Colloid Surface A. 2005;269:47-58.

[20] American Nuclear Society. Measurement of the leachability of solidified low-level radioactive wastes by a short-term test procedure ANSI/ANS-16.1-2003. Illinois; 2004.

[21] Lehto J, Brodkin L, Harjula R, Tusa E. Separation of radioactive strontium from alkaline nuclear waste solutions with the highly effective ion exchanger SrTreat. Nucl 
Technol. 1999;127:81-87.

[22] Wang Y, Liu H. Preparation and characterizations of $\mathrm{Na}_{2} \mathrm{Ti}_{3} \mathrm{O}_{7}, \mathrm{H}_{2} \mathrm{Ti}_{3} \mathrm{O}_{7}$ and $\mathrm{TiO}_{2}$ nanobelts. J Adv Mater Res. 2011;306-307:1233-1237.

[23] Andersson S, Wadsley $\mathrm{AD}$. The crystal structure of $\mathrm{Na}_{2} \mathrm{Ti}_{3} \mathrm{O}_{7}$. Acta Crystallogr. $1961 ; 14: 1245-1249$.

[24] Li N, Zhang L, Chen Y, Fang M, Zhang J, Wang H. Highly efficient, irreversible and selective ion exchange property of layered titanate nanostructures. Adv Funct Mater. $2012 ; 22: 835-841$.

[25] Yusuke I, Masahiro S, Tsuneji S, Makoto O. Functionalization of layered titanates. J Nanosci Nanotechno. 2014;14:2135-2147.

[26] Ali IM. Synthesis and sorption behavior of semicrystalline sodium titanate as a new cation exchanger. J Radioanal Nucl Ch. 2004;260:149-157.

[27] Yang J, Li D, Wang X, Yand X, Lu L. Study on synthesis and ion-exchange properties of layered titanate $\mathrm{Na}_{2} \mathrm{Ti}_{3} \mathrm{O}_{7}$ powders with different sizes. $J$ Mater Sci. 2003;38:2907-2911.

[28] Lehto J, Clearfield A. The ion exchange of strontium on sodium titanate $\mathrm{Na}_{4} \mathrm{Ti}_{9} \mathrm{O}_{20} \mathrm{X}$ $\mathrm{H}_{2} \mathrm{O}$. J Radioanal Nucl Ch. 1987;1:1-13.

[29] Lehto J, Harjula R, Girard A-M. The equilabrium of strontium ion exchange on sodium titanate, $\mathrm{Na}_{4} \mathrm{Ti}_{9} \mathrm{O}_{20} \times \mathrm{H}_{2} \mathrm{O}$. J Chem Soc. 1989;1:101-103.

[30] Takahatake Y, Shibata A, Nomura K, Sato T. Effect of flowing water on Sr sorption changes. Minerals. 2017;7:247-260.

[31] Duxson P, Fernández-Jiménez A, Provis JL, Lukey GC, Palomo A, Van Deventer JSJ. Geopolymer technology: The current state of the art. J Mater Sci. 2007;42:2917-2933.

[32] Lizcano M, Kim HS, Basu S, Radovic M. Mechanical properties of sodium and potassium activated metakaolin-based geopolymers. J Mater Sci. 2012;47:2607-2616.

[33] Kuenzel C, Cisneros JF, Neville TP, Vandeperre LJ, Simons SJR, Bensted J, 
Cheeseman CR. Encapsulation of $\mathrm{Cs} / \mathrm{Sr}$ contaminated clinoptilolite in geopolymers produced from metakaolin. J Nucl Mater. 2015;466:94-99.

[34] Sakamoto N, Yurimoto H. Highly sensitive ion imaging system using direct combination of a stacked-type solid-state imager and microchannel plate driven by LanVIEW softwear. Surf Interface Anal. 2006;38:1760-1762.

[35] Sakamoto N, Itoh S, Yurimoto H. Discovery of 17,18 O-rich material from meteorite by direct-imaging method using stigmatic-SIMS and 2D ion detector. Appl Surf Sci. 2008;255(4):1458-1460.

[36] Walkley B, Ke X, Hussein OH, Bernal SA, Provis JL. Incorporation of strontium and calcium in geopolymer gels. J Hazard Mater. 2020;382:121015-121024. 


\section{Figure}



Figure 1. XRD pattern of the metakaolin precursor

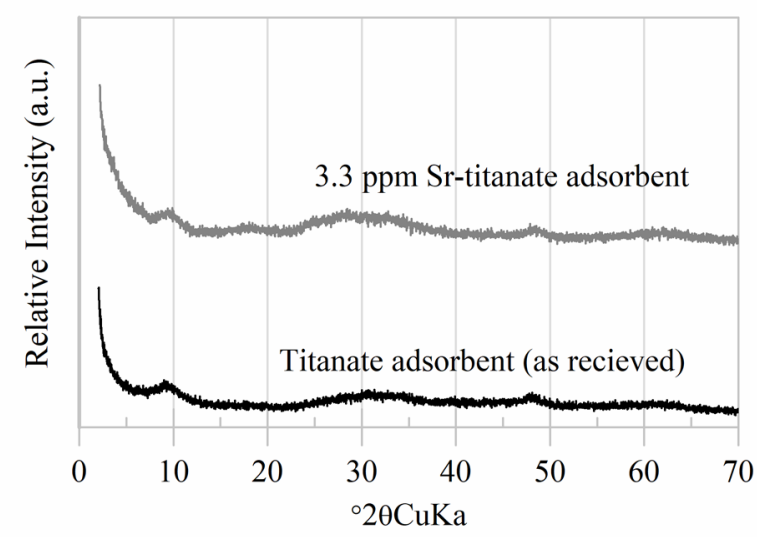

Figure 2. XRD patterns of titanate adsorbent before and after loading with $\mathrm{Sr}^{2+}$

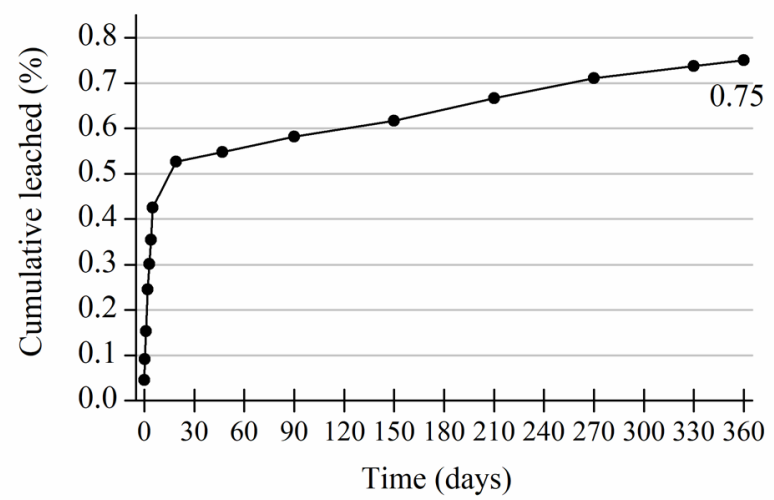

Figure 3. Cumulative leaching of $\mathrm{Sr}^{2+}$ from geopolymer mixed with titanate adsorbent, applying the ANSI/ANS 16.1 test method with full replacement of leachate at each sampling 
point shown

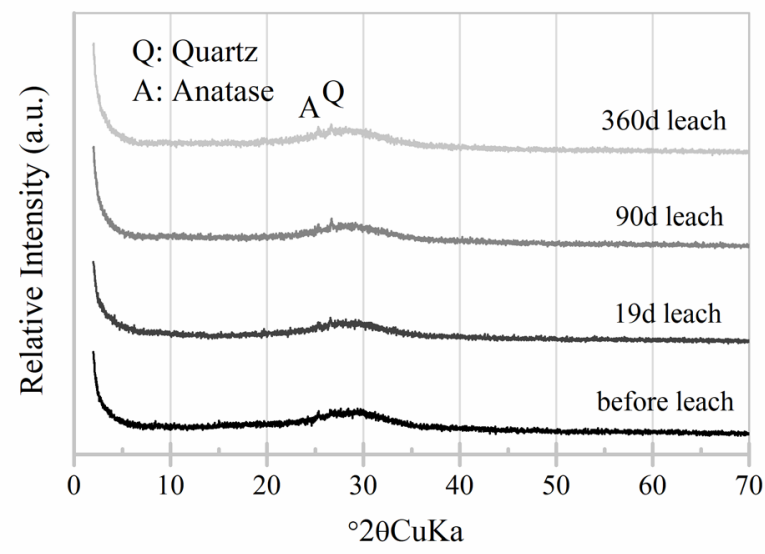

Figure 4. XRD patterns of K-geopolymer with spent titanate adsorbent before and after leaching for different durations as marked

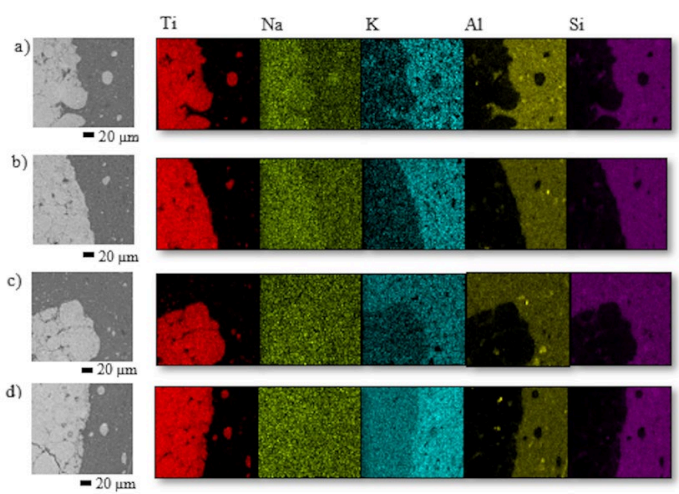

Figure 5. SEM images and elemental maps of specimens with titanate adsorbent; a) before, and after b) 19days, c) 90days, and d) 360 days of leaching in deionized water 

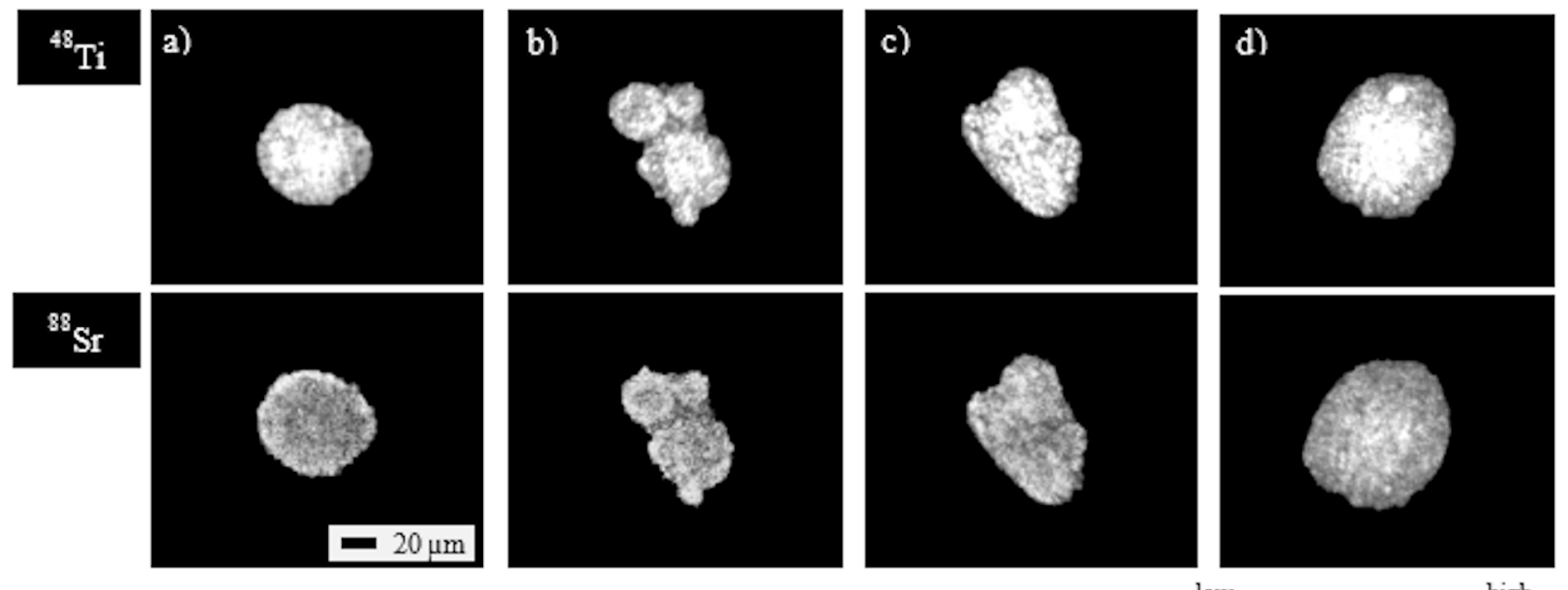

low

Figure 6. $\quad{ }^{48} \mathrm{Ti}$ and ${ }^{88} \mathrm{Sr}$ isotope maps surrounding a titanate adsorbent particle in geopolymer specimens a) before, and after b) 19 days, c) 90 days, and d) 360 days of leaching in deionized water

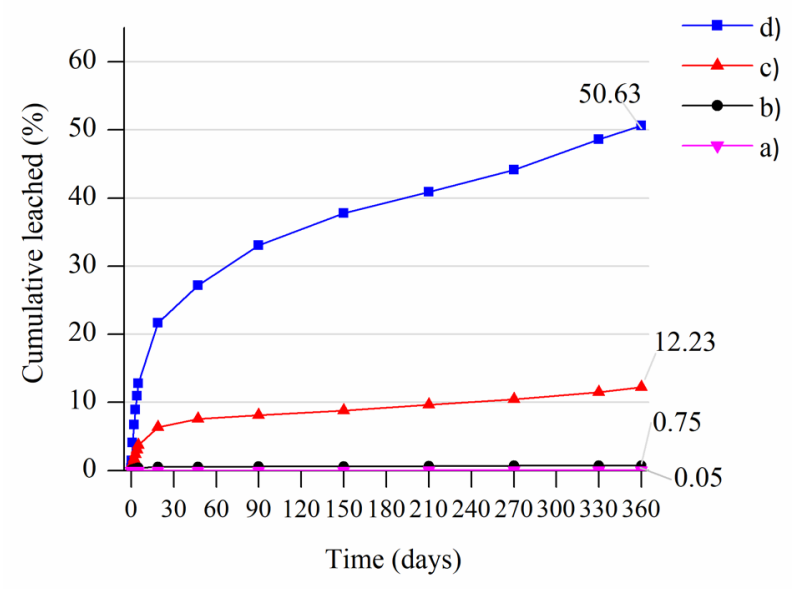

Figure 7. Cumulative leached percentage of $\mathrm{Sr}^{2+}$ from: a) geopolymer without adsorbent,

b) geopolymer with adsorbent, c) cement with adsorbent, d) cement without adsorbent 

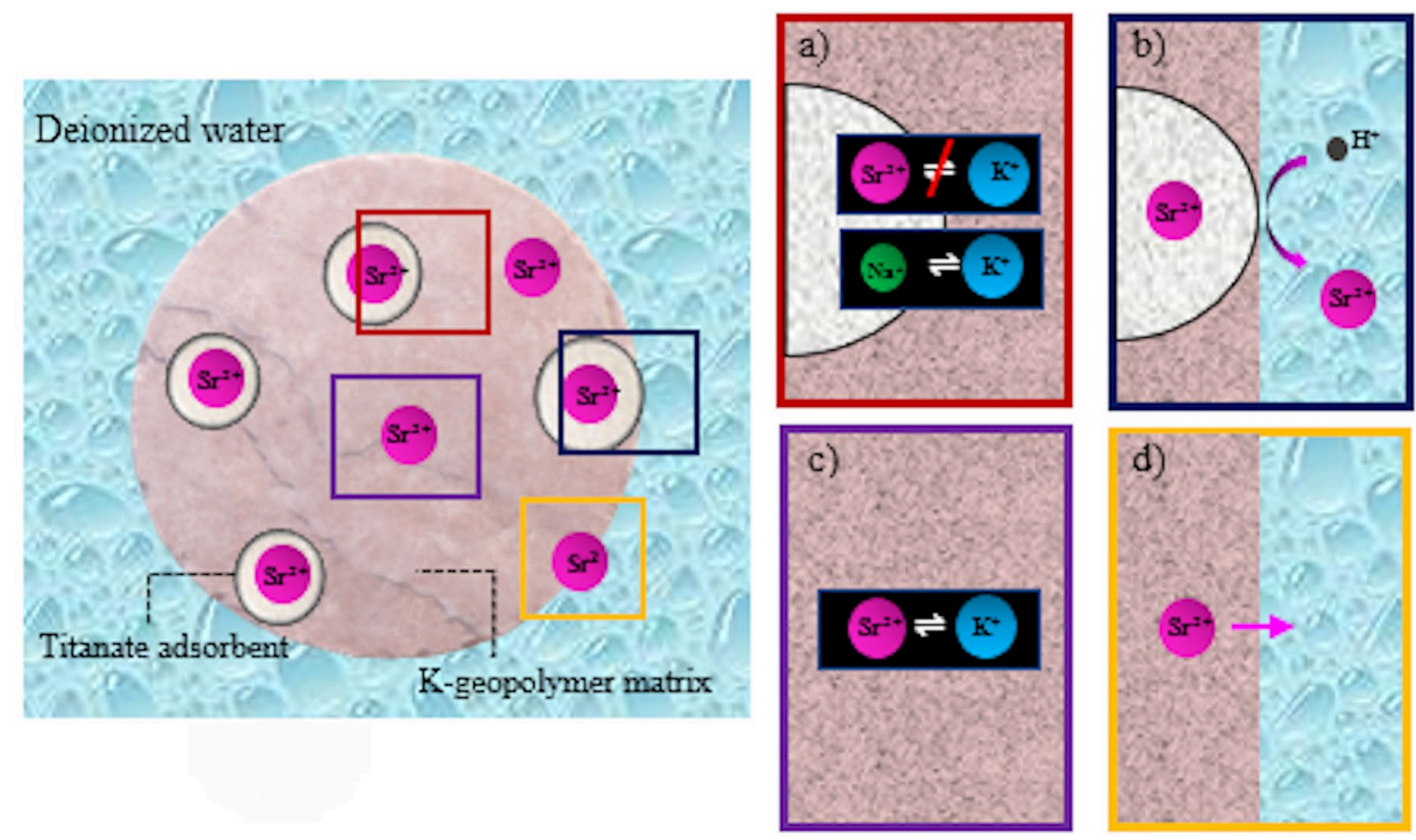

Figure 8. Schematic diagram of geopolymer matrix encapsulated titanate adsorbent adsorbed strontium, the interaction where a) between titanate adsorbent and geopolymer matrix inside specimen, b) the edge between titanate adsorbent and deionized water, c) geopolymer binder area, d) the edge between geopolymer matrix and deionized water. 